\title{
Docente Integrador: una experiencia de trabajo colaborativo entre docentes de educación superior Integrative Teaching: an experience of collaborative work among higher education teachers.
}

\author{
Gómez Flores, Bryan Israel ${ }^{1}$, Esparza González, Elvia Isabel ${ }^{2}$, Briceño Preciado, Nuve Liliana ${ }^{3}$, \\ Andrea Patricia, Loaiza Peña ${ }^{4}$, Paola Salomé, Andrade Abarca ${ }^{5}$, Loaiza Aguirre, María Isabel ${ }^{6}$ \\ bigomez@utpl.edu.ec ${ }^{1}$, eiesparza@utpl.edu.ec ${ }^{2}$,nlbriceno@utpl.edu.ec ${ }^{3}$, \\ aploaizax@utpl.edu.ec ${ }^{4}$,psandrade@utpl.edu.ec ${ }^{5}$, miloaiza@utpl.edu.ec ${ }^{6}$ \\ Universidad Técnica Particular de Loja, \\ Loja, Ecuador
}

\begin{abstract}
Resumen- El proceso de adaptación a la vida universitaria muestra cierta complejidad en los estudiantes de primer ingreso, en donde, el cambio metodológico que experimentan puede representar una brecha entre el nuevo entorno académico, al cual deben integrarse. El proyecto Docente Integrador, busca generar una sinergia entre el proceso de enseñanza-aprendizaje, entre diferentes asignaturas ofertadas en el primer año de la universidad, alcanzando por medio del trabajo colaborativo, una planificación estructurada y organizada que permita desarrollar las competencias requeridas, velando por la permanencia de dichos estudiantes en sus programas académicos. En este trabajo se expone, a través de la percepción de docentes de primer semestre que participaron del proyecto, el nivel de satisfacción en cuanto a la implementación y resultados obtenidos a partir de la figura del docente integrador.
\end{abstract}

Palabras clave: trabajo colaborativo, profesorado, educación superior, universidad, estudiantes universitarios.

Abstract- The process of adaptation to university life shows some complexity in first year students, where the methodological change they experience may represent a gap between the new academic environment to which they must integrate. The Integrating Teaching Project seeks to generate a synergy between the teaching-learning process of different subjects offered in the first year of the university, achieving through collaborative work, a structured and organized planning that allows developing the required competencies, ensuring the permanence of these students in their academic programs. This paper presents, through the perception of first semester teachers who participated in the project, the level of satisfaction with the implementation and results obtained from the figure of the integrating teacher.

Keywords: collaborative work, faculty, higher education, university, university students.

\section{INTRODUCCIÓN}

Durante el proceso de enseñanza-aprendizaje de los estudiantes se requiere el trabajo integral y coordinado del profesorado.

El trabajo colaborativo entre docentes genera procesos de innovación y mejora de las instituciones educativas (Krichesky y Murillo, 2018). Es un proceso en el cual un individuo puede aprender más de lo que podría aprender por sí solo, como consecuencia de la interacción entre los miembros del grupo, potenciando de esta manera la construcción del conocimiento (Revelo - Sánchez et al., 2018). El desarrollo profesional de los docentes puede desarrollarse de manera independiente y autónoma, sin embargo, su formación también puede no ocurrir de manera aislada, sino por medio de la interacción cooperativa y comunitaria entre colegas (Vaillant, 2016).

Actualmente, podría considerarse que el trabajo en equipo es una necesidad más común entre las organizaciones actuales, incluidas las del ámbito educativo, cuya finalidad es la de poder enfrentar una realidad cambiante y muchas veces impredecible (Walss et al., 2008). Algunas de las lecciones que se ha aprendido acerca del trabajo colaborativo entre docentes, es lo dificultoso que resulta poder ponerlo en práctica, ya sea por la estructura de las propias organizaciones, o por la falta de destrezas vinculadas al trabajo en equipo (Krichesky y Murillo, 2018). En este sentido, resulta clave, que las relaciones colaborativas sean entendidas como una vía a través de la cual los docentes salgan de su "zona de confort" para establecer relaciones con sus pares, a fin de lograr objetivos comunes (Molina y López, 2019).

Dentro del contexto educativo, el trabajo colaborativo constituye un modelo de aprendizaje interactivo, que involucra a los estudiantes, además de demandar esfuerzo, talentos y competencias para el logro de metas (Revelo - Sánchez et al., 2018). En cuanto al papel de los docentes, el aprendizaje colaborativo es una estrategia de desarrollo profesional docente, en la cual pueden compartir experiencias, además de analizar e investigar sobre sus prácticas pedagógicas (Vaillant, 2016). El trabajo colaborativo se deriva de la cultura institucional, para lograr objetivos comunes (Molina y López, 2019).

La autorregulación existente en la comunidad de aprendizaje es un aspecto muy importante en su vida. En el terreno educativo, el aprendizaje en equipo es el proceso mediante el cual los profesores se agrupan y desarrollan la capacidad de trabajar juntos para alcanzar los resultados que ellos esperan.

Krichesky y Murillo (2018), en su trabajo denominado "La colaboración docente como factor de aprendizaje y promotor de mejora. Casos de estudio", mencionan que, bajo ciertas 
condiciones, la colaboración puede convertirse en una alternativa de trabajo muy atractiva para el colectivo docente, así como, una estrategia de mejora. Esto también puede verse reflejado en nuevas oportunidades de desarrollo profesional, con base en la reflexión que se comparte entre pares. El aprendizaje colaborativo es un sistema de interacciones que promueve la influencia recíproca entre los integrantes de un equipo, se trata de un proceso gradual en el que todos los miembros se comprometen con el aprendizaje de los demás, resultando en una colaboración positiva (Revelo - Sánchez et al., 2018).

Además, este tipo de trabajo genera una formación y autoaprendizaje entre colegas, el cual se conoce como "feedback", ya que cada docente contribuye con su conocimiento al grupo, formando una comunidad de aprendizaje, aportando y recibiendo conocimiento a través de las diferentes experiencias vividas por los docentes que integran esta comunidad (Montaño et al., 2017).

Entre los principios claves que permiten el desarrollo del trabajo colaborativo entre docentes se debe tener presente: a) La unión de los esfuerzos del grupo para solucionar los problemas presentados en los estudiantes, b) Implementar acciones innovadoras en las que cada miembro aporta como individuo complementando las acciones del grupo, c) El diálogo y comunicación permanente que se genera en el grupo.

El propósito del trabajo colaborativo es el de ayudar, estimular y motivar, la participación de cada miembro de la comunidad, asegurando el crecimiento profesional y personal, que contribuya al desarrollo de todo el equipo. El trabajo colaborativo es un proceso de construcción social, en el que cada individuo aprende más de lo que aprendería por sí solo, debido a la interactividad con otros miembros de su grupo (Navarro \& López, 2017).

\section{CONTEXTO}

El éxito o fracaso en la integración de un estudiante nuevo a sus estudios de educación superior, tiene dos vertientes distintas y relacionadas, por un lado, están propiamente los estudios, que sin duda se complementan a lo concerniente a la integración a la vida universitaria, vinculado a crecer en su madurez humana; para ello, se vuelve fundamental, que las universidades tomen una actitud activa ante la llegada de los nuevos estudiantes, atiendo a interrogantes como, ¿Cuál debe ser la posición institucional con respecto a sus nuevos alumnos?, ¿Cómo los ven?, ¿Con qué predisposición los reciben?, ¿Cómo los orientan?, ¿Cómo se comprometen con ellos?; con respuestas tan diversas como los intereses de los estudiantes actuales, diferentes en expectativas, origen, o en su implicación (Michavila Pitarch, 2015).

Ante esta situación, la presente investigación describe las prácticas asumidas por una universidad latinoamericana de amplia trayectoria académica, que ha dado protagonismo a la implementación de metodologías educativas de tipo participativo y colaborativas entre docentes, para apoyar el proceso de adaptación de sus alumnos nuevos. El proyecto Docente Integrador, se fundamenta en la constitución de equipos docentes, que comparten el objetivo común de mejorar la integración de alumnos nuevos, a través de la planificación y coordinación, basada en un trabajo colaborativo.

En el marco del presente proyecto, la creación del rol del docente integrador, tiene la finalidad de fomentar el trabajo colaborativo e integrar la planificación que realizan los profesores de primer ciclo de la carrera, con el objetivo de que todas las asignaturas que se ofertan en este ciclo, cuenten con una planificación estructurada, organizada y que desarrollen las competencias requeridas.

Esta experiencia se ha contextualizado en Ecuador, país en donde el sistema universitario ha tenido una gran transformación en los más recientes años, focalizándose en un diagnóstico de la experiencia percibida por un grupo de docentes de estudiantes nuevos de la modalidad presencial, pertenecientes a carreras de diferentes áreas disciplinares, durante el curso 2020-2021, con el objetivo de conocer su percepción sobre los resultados del proyecto, como un medio para valorar su funcionamiento.

\section{DESCRIPCIÓN}

Para este proyecto, participaron profesores de primeros ciclos de todas las carreras de la Universidad Técnica Particular de Loja, modalidad presencial, durante el año 2020 - 2021.

El proyecto se fundamenta en las funciones encargadas al docente integrador, las cuales consisten en: (1) Conformar un grupo de trabajo con todos los docentes de primer ciclo y fomentar el trabajo interdisciplinar y en equipo; (2) Coordinar la planificación integrada de contenidos y número de actividades propuestos en el plan docente de todas las asignaturas que se dictan en primer ciclo en la titulación; (3) Velar por la permanencia de los estudiantes de primer ciclo en la titulación y en la universidad; (4) Trabajar de manera coordinada con los estudiantes mentores de alumnos nuevos, con la finalidad de solventar las dificultades detectadas en los estudiantes.

Las tareas realizadas durante el desarrollo del proyecto siguieron el siguiente orden: (1) Seguimiento al cumplimiento de actividades del Docente Integrador; (2) Diseño de cuestionario para evaluar logros obtenidos de aplicar el proyecto; (3) Aplicación: informatización del cuestionario en línea, que fue subido a la herramienta e-encuesta; (4) Análisis de datos estadísticos; y (5) Informe final y propuestas de mejora.

La metodología de investigación seleccionada, fue no descriptiva y no experimental, ya que no se cambia el objeto de estudio, ni se interviene directamente sobre las variables, sino, simplemente se registra sus medidas (Kerlinger y Lee, 2002). Se optó por el estudio de encuesta, a partir de un instrumento de recogida de datos de naturaleza cuantitativa y, se utilizó el formato de encuesta estructurada en línea.

El cuestionario se organizó en 3 unidades de contenido: (1) Información general (género, años de experiencia y titulación); (2) Desenvolvimiento del Docente Integrador; (3) Valoración General del Proyecto Docente Integrador.

Muestra 
El presente estudio, se basa en una población de profesores de primer ciclo, de todas las carreras de modalidad presencial de la UTPL durante el año 2020-2021.

Se trabajó con una muestra no probabilística de 138 profesores de 29 carreras de modalidad presencial, en donde los participantes respondieron voluntariamente al cuestionario.

Las variables para el presente estudio, se definieron en base a las funciones establecidas dentro del proyecto, para lo cual se construyó un cuestionario de 15 ítems con una escala Likert de cinco grados, asociada a valores de: (1) Insatisfactorio; (2) Poco satisfactorio; (3) Regular; (4) Satisfactorio; y (5) Muy satisfactorio.

\section{Resultados}

\subsection{Datos Generales}

Los resultados muestran equidad en cuanto al género de los docentes participantes en la encuesta de satisfacción, registrando un $48.31 \%$ de mujeres y $51.69 \%$ en el género masculino.

En cuanto a la experiencia dentro de la docencia universitaria, existe una mayor concentración de docentes con más de 10 años de experiencia, los cuales representan el 41,58\% de los participantes en la encuesta, seguido por el $24,75 \%$ con experiencia de 3 a 6 años, finalmente, el $17,82 \%$ y $15,84 \%$ se componen por docente de experiencia de 0 a 2 años y 7 a 6 años respectivamente.

Gráfica 1. Se muestra como está compuesta la participación de los docentes en la encuesta de satisfacción por áreas, en donde, el resultado se ve influenciado por el número de carreras que las componen. De esta manera, el Área Biológica y Biomédica, refleja una mayor participación con un 38,54\%, y el Área Administrativa registra la menor participación con el $13,54 \%$.

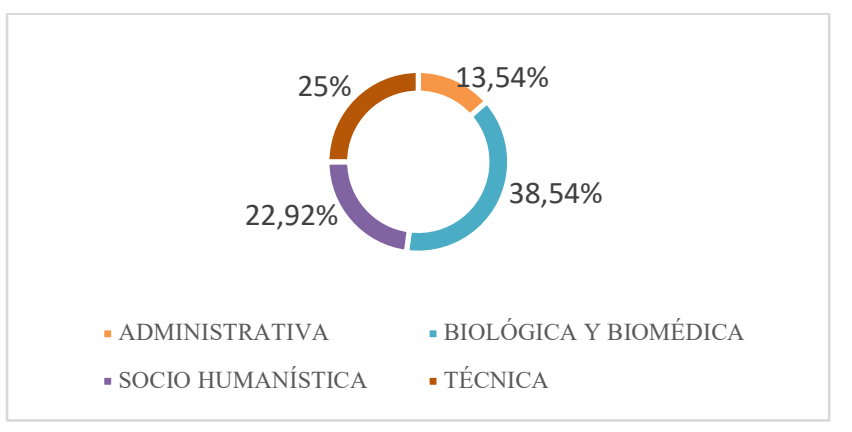

Gráfica 1. Docentes participantes en la encuesta, por área y carrera.

4.2 Desenvolvimiento del docente integrador

Gráfica 2. La percepción de los docentes participantes de la encuesta de satisfacción, en cuanto a propiciar un ambiente participativo y de confianza para expresar propuestas que promuevan el trabajo efectivo dentro del proyecto, así como, el cumplimiento a las reuniones planificadas para dar seguimiento a las actividades propuestas dentro del mismo, son valoradas en un porcentaje mayor al $60 \%$ como muy satisfactorias, a la vez, no se registran valoraciones clasificadas en la escala como insatisfactorio ni poco satisfactorio.

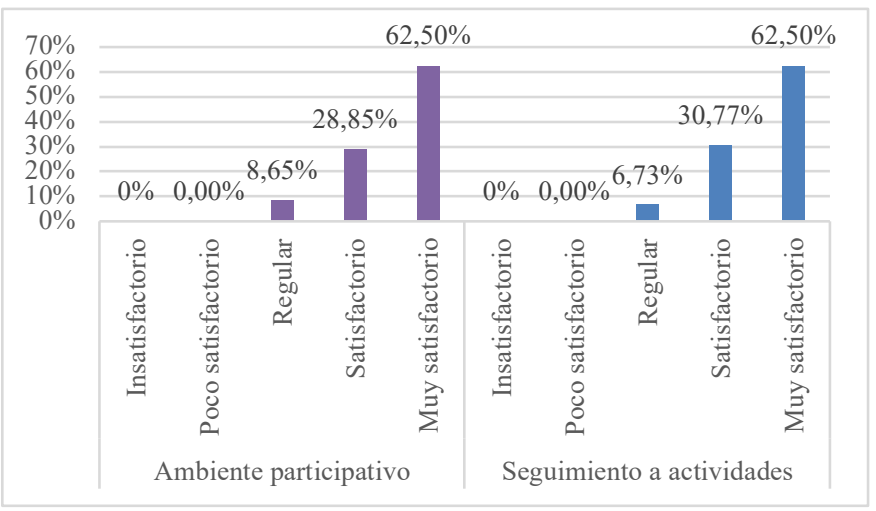

Gráfica 2. Valoración ambiente participativo y seguimiento de actividades.

Gráfica 3. Se muestra la valoración obtenida por la figura del docente integrador, en actividades relacionadas con: (a) Conformar un grupo interdisciplinario y fomentar el trabajo en equipo con todos los docentes de primer ciclo de la titulación, y (b) Impulsar la participación del grupo de docentes, promoviendo actividades para mejorar el nivel de aprendizaje de los estudiantes de primer ciclo. En estas actividades no se identifica insatisfacción de parte de los docentes participantes $\mathrm{y}$, la valoración |clasificada en la escala como poco satisfactorio es relativamente baja, en donde el mayor porcentaje se distribuye entre muy satisfactorio y satisfactorio, abarcando entre estas dos, cerca del $90 \%$ de participantes

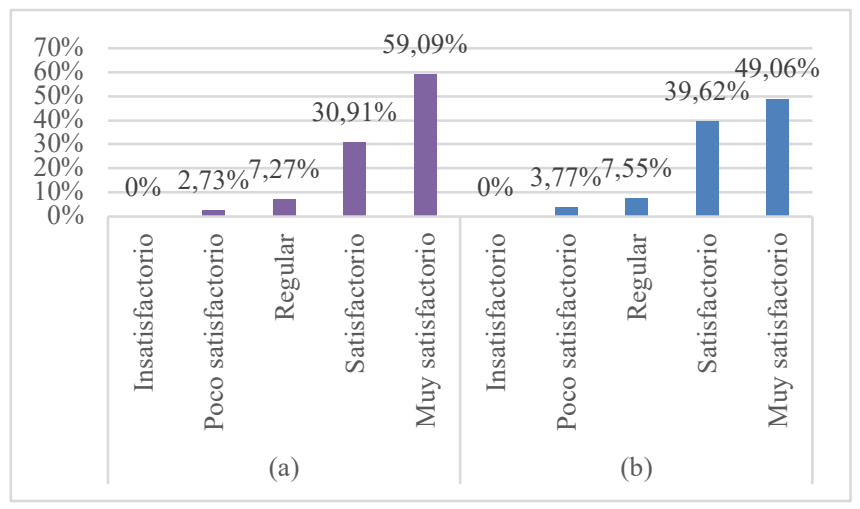

Gráfica 3. Valoración de actividades a y b.

Gráfica 4. Esta gráfica representa la valoración obtenida en cuanto a actividades como: (c) Coordinar la planificación integrada de contenidos y número de actividades propuestas en el plan docente de todas las actividades dictadas en primer ciclo y (d) Promover la integración del grupo de docentes en la revisión del tiempo de dedicación de las actividades propuestas en el plan docente, evitando sobrecargas de trabajo. En ambas actividades, la percepción es bastante aceptable, ya que cerca del $90 \%$ de la valoración se distribuye entre muy satisfactorio y satisfactorio, además, no se observa insatisfacción de parte de ninguno de los participantes y existe un bajo porcentaje situado en poco satisfactorio. 


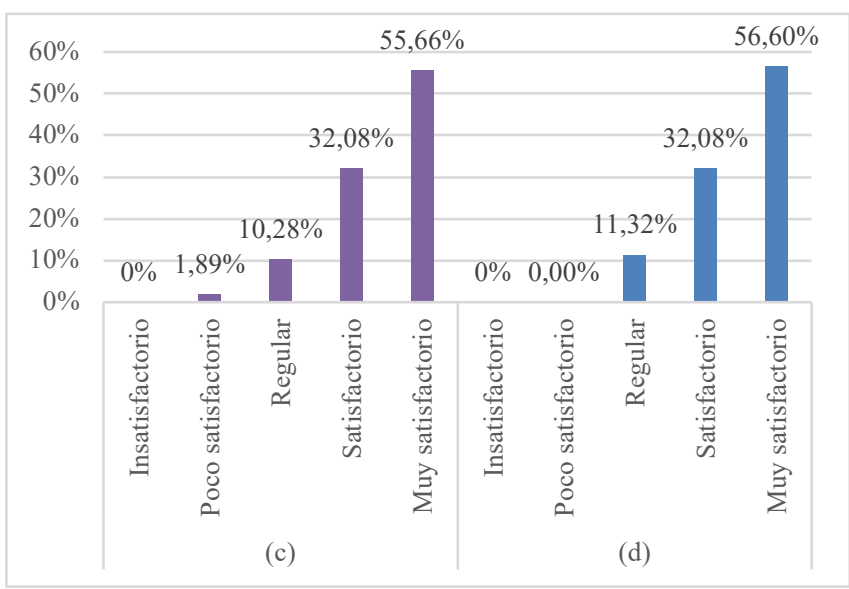

Gráfica 4. Valoración de actividades $c$ y $d$.

Gráfica 5. La valoración obtenida en la actividad: (e) Intercambio de ideas para el manejo y resolución de problemas suscitados en los estudiantes de primer ciclo con el fin de velar por su permanencia en la carrera, concentra mayormente entre muy satisfactorio y satisfactorio al $61,5 \%$ y $30,3 \%$ respectivamente, completando entre estas dos valoraciones al $91,8 \%$ de docentes

\begin{tabular}{lr|l|}
\hline Respuesta & Porcentaje \\
\hline Insatisfactorio & $0.00 \%$ & \\
\hline Poco satisfactorio & $0.98 \%$ & \\
\hline Regular & $8.82 \%$ & \\
\hline Satisfactorio & $38.24 \%$ & \\
\hline Muy satisfactorio & $51.96 \%$ & \\
\hline
\end{tabular}

\section{Gráfica 5. Valoración de actividad (e)}

Gráfica 6. Los profesores encuestados, perciben de manera positiva la labor realizada por el docente integrador, en donde el $66,35 \%$ de ellos, lo consideran como muy satisfactorio y, un $26,92 \%$ como satisfactorio, siendo estas dos percepciones en las cuales existe una mayor concentración de respuestas, además, es importante mencionar que, dentro de la valoración, no se identifica un nivel de insatisfacción por parte de los participantes.

\begin{tabular}{|l|l|}
\hline Respuesta & Porcentaje \\
\hline Insatisfactorio & $0.00 \%$ \\
\hline Poco satisfactorio & $1.92 \%$ \\
\hline Regular & $4.81 \%$ \\
\hline Satisfactorio & $26.92 \%$ \\
\hline Muy satisfactorio & $66.35 \%$ \\
\hline
\end{tabular}

Gráfica 6. Percepción de la labor del docente integrador.
Gráfica 7. Finalmente, la valoración general de los docentes de primer ciclo, respecto a los resultados obtenidos con la implementación del proyecto "Docente integrador", muestra que un porcentaje equivalente al $51,96 \%$, consideran que ha sido muy satisfactorio, logrando entre esta valoración, y la valoración de satisfactorio, una percepción positiva de al menos el $90 \%$ de docentes involucrados.

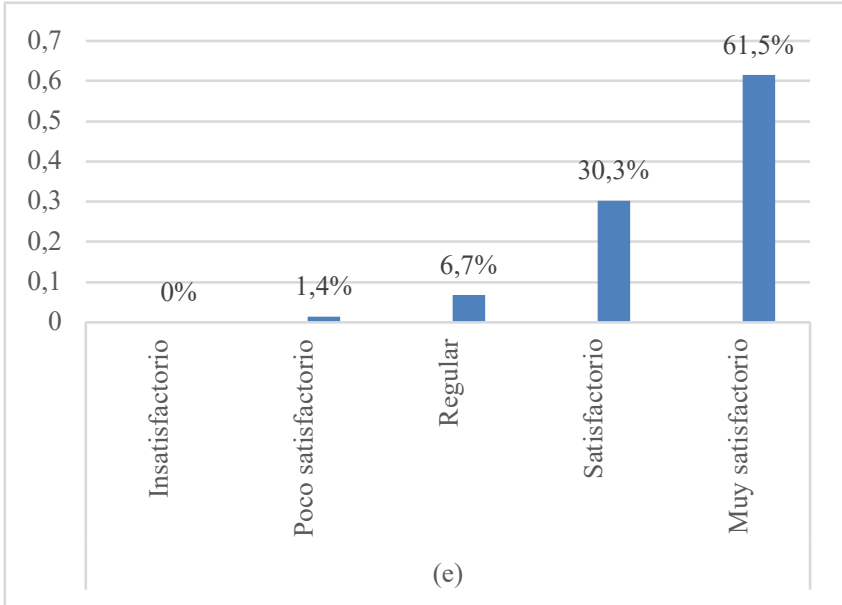

Gráfica 7. Percepción acerca de resultados obtenidos.

\section{CONCLUSIONES}

Bajo la propuesta del proyecto, se evidencia que el trabajo colaborativo horizontal entre docentes universitarios asignados a materias de primer año muestra niveles muy satisfactorios en cuanto a establecer un ambiente participativo y dar paso al seguimiento de las actividades planificadas, lo que muestra la efectividad del proyecto, siendo lo mas destacable el fomento de un trabajo en equipo encaminado a establecer estrategias para la mejora del aprendizaje de alumnos nuevos.

De cara a la permanencia de los estudiantes de nuevo ingreso en la universidad, el trabajo colaborativo de los docentes ha influido satisfactoriamente, logrando solucionar problemas presentados en la transición del bachillerato a la universidad.

El contar con un líder, que bajo la figura del docente integrador, coordine las actividades planificadas por los docentes de primer año, ha ayudada al desarrollo de los proyectos curriculares de cada carrera, garantizando una integración y equilibrio entre la distribución de actividades.

Sin duda, esta experiencia puede ser transferible a otros contextos universitarios, en los que el foco además de reforzar los procesos de inserción de alumnos nuevos, puede estar orientado a fortalecer el proceso de enseñanza-aprendizaje en otros niveles a través de un trabajo vertical e interdisciplinar.

El seguimiento oportuno de las actividades propuestas dentro del proyecto, así como la evaluación de los resultados obtenidos, son prácticas que deben prevalecer en programas de similares características con la finalidad de alcanzar los objetivos propuestos y promover la mejora continua. 


\section{REFERENCIAS}

Kerlinger, F. \& Lee, H. (2002). Investigación del comportamiento (1 ra Ed.). México: McGraw-Hill Interamericana.

Krichesky, G. J., \& Murillo, F. J. (2018). La colaboración docente como factor de aprendizaje y promotor de mejora. Un estudio de casos. Educación XX1, 21(1), 135-155.

Michavila Pitarch, F. (2015). La acogida de los nuevos estudiantes. REDU. Revista de Docencia Universitaria, 13(2),

37. https://doi.org/10.4995/redu.2015.5437

Molina, C. A., \& López, F. S. (2019). Trabajo colaborativo docente: nuevas perspectivas para el desarrollo docente. Psicología Escolar e Educacional, 23.

Montaño, M. J. N., Martínez, A. L., \& de la Torre, M. E. H. (2017). El trabajo colaborativo en red impulsor del desarrollo profesional del profesorado. Revista Brasileira de Educacao, 22(70), 651-667. https://doi.org/10.1590/S1413-24782017227033

Navarro Montaño, María \& López Martínez, Antonia \& Hernández de la Torre, Elena. (2017). El trabajo colaborativo en red impulsor del desarrollo profesional del profesorado. Revista Brasileira de Educação. 22. 651667. 10.1590/s1413-24782017227033.

Revelo-Sánchez, O., Collazos-Ordóñez, C. A., \& JiménezToledo, J. A. (2018). El trabajo colaborativo como estrategia didáctica para la enseñanza/aprendizaje de la programación: una revisión sistemática de literatura. TecnoLógicas, 21(41), 115-134.

Vaillant, D. (2016). Trabajo colaborativo y nuevos escenarios para el desarrollo profesional docente. Revista docencia, 60, 7-13.

Walss, M., \& Valdés, U. (2008). El Trabajo Colaborativo como herramienta de los docentes y para los docentes. Laguna: ITESM. 